\title{
Attitudes of School Teachers about Roma Inclusion in Education, A Case Study of Vojvodina, Serbia
}

\author{
Jelena Milanković ${ }^{A}$, Anđelija Ivkov-Džigurski ${ }^{A}$, Smiljana Đukičin ${ }^{A}$, \\ Ljubica Ivanović Bibić ${ }^{A}$, Tin LukićA, Kristina Kalkan ${ }^{A}$ \\ Received: May 19, 2015 | Revised: August 23, 2015 | Accepted: September 1, 2015
}

\begin{abstract}
Roma in Serbia still do not have equal access to quality education. Roma children are more increasingly present in the school system in Serbia, which shows that there is a trend in decreasing differences among pupils.

Inclusion should make education more accessible and of better quality for Roma children. Serbia is on the right track to achieve this. It started with introducing Roma assistants in teaching, who would help Roma children fit into the educational system. The introduction of elements of national cultures, including Romani, would make schooling much more attractive to Roma children, because it would reflect their living environment and contribute to a better acceptance of Roma children by other children and teachers.

The first part of the paper with descriptive method tells about the status of the Roma in Serbia and their problems in education, as well as ways to improve the conditions of their education. Statistical method was used to display present and situation in past. Experimental part of this paper demonstrates attitudes of primary and secondary school teachers in Novi Sad, the Autonomous Province of Vojvodina, about the inclusion of Roma children in education.
\end{abstract}

Key words: Roma, inclusion, education, Vojvodina, Serbia

\section{Introduction}

The Roma (singular Rom), or as they are more commonly known in the English speaking world, the Gypsies (Egyptians) entered Europe in the late Middles Ages from India. Elsewhere, the Roma are referred to as cigán, tsiganes, zigeuner, and other similar terms. These names come from the Byzantine Greek word, Atsinganoí, which means itinerant wanderers or soothsayers. Because of the stereotypes and prejudice associated with these names, the Gypsies preferred to be called Roma or Romani, a name from their own language, Romani (Crowe, 2001; Székelyi, et al., 2003).
It is estimated that there are between 8 and 12 million of Roma across Europe and they represent one of the biggest and the most endangered minorities. They are mostly excluded from numerous aspects of society, deprived from their rights and trapped in poverty. In particular, Roma face problems regarding the possibilities of accessing quality education (Claude, et al., 1999; Kyuchukov, 2000; Tanner, 2005; Hemelsoet, 2015).

In the Republic of Serbia, Roma children do not have equal access to quality education and this is one of the main reasons why Serbia is participating in the "Decade of Roma Inclusion 2005-2015". The Decade

\footnotetext{
A University of Novi Sad, Faculty of Sciences, Department of Geography, Tourism and Hotel Management, Trg Dositeja Obradovića 3, 21000 Novi Sad, Serbia

Corresponding author: Jelena Milanković, e-mail: milankovicj@hotmail.com
} 
was established with the aim to eradicate discrimination and diminish inequalities in various spheres of life, such as housing, employment, health care, education... (Open Society Institute, 2007).

The aim of this research is to point out the significance of inclusive Roma education in Vojvodina and Serbia, which should provide equal rights of education and self-improvement for everyone. Attitudes of teachers about Roma inclusion are crucial element of this paper because the conducted research treats teachers' opinions and their evaluation of inclusion separately. A part of this research also refers to teachers' experience in inclusion, which represents the essential part of this paper. Data acquired in the research are processed by SPSS Statistics. The basic objective of this paper is to show how important inclusion is for a society and to urgently implement all the measures needed for future generations to get quality education, which will provide higher employment and active participation in the society.

\section{Roma in Serbia}

Roma in the Balkans and in Serbia have appeared since 16 th century, simultaneously with the Turkish invasion. Based on their origin, language and religious beliefs, we can distinguish four groups: (a) Turkish Roma, who are Muslims or Christians by their religious beliefs, (b) White Roma, who came from Bosnia and who belong to Muslim religion and speak Serbian, (c) Vlach Roma who came from Romania and who belong to orthodox religion and speak Serbian and (d) Hungarian Roma who came from Austria (UNDP, 2005a).

The origins of Roma in Vojvodina are very hard to be established, because many of them do not know where their ancestors came from. Individual families came from Bulgaria to Bačka, and from Ukraine (from the place called Sartov) or from Romania to Banat (Ivkov, 2006).

Official records about Roma population are mainly considered to be unreliable - it is supposed that their number in population censuses is underestimated, since they, because of fear from being discriminated, declare themselves differently. However, this is not only the case in Serbia. According to the regional report of UNDP, which encompasses five countries of Eastern and Central Europe, less than half of Roma declared themselves Roma in the last population censuses(UNDP, 2005b). Since they are striking and dynamic because of their frequent appearance in public places (streets, markets, cemeteries, etc.), there is a real impression that there are more Roma in some of the communities in Vojvodina then it is statistically recorded (Kicošev, 1997).
After relatively successful response of Roma to Censuses 1948 and 1953(when 46,869 Roma were recorded), Census 1961 registered only 6,624 persons in Roma community. Since then, the number of Roma has continuously been growing, so in 2002, it reaches the number of 108,193 persons. According to the latest population census from 2011 there are 147,604 Roma, in other words they make $2.0 \%$ of the total number of people in Serbia, that is of $7,186,862$ persons. Children aged up to 15 years make almost one third or $32.2 \%$ of that number(Statistical Office of the Republic of Serbia, 2014). In the past, instead of declaring their own identity, Roma often inclined towards the members of majority communities, i.e. they declared themselves as members of the community they lived in. In the existing scientific papers, this phenomena has often been described as "ethnic mimicry of Roma".

There are many unofficial estimates of the size of Roma population, but their validity is questionable because of a large number of unregistered persons, especially those who came to Serbia during 199 os as refugees or internally displaced persons (IDP) from other countries of former Yugoslavia and the territory of Kosovo. In addition to that, since the year 2000, repatriation of Roma from the countries of the European Union (EU) has started, which has resulted in tens of thousands of newcomers, persons who also did not often have any identification documents. Some researchers estimate that the total number of Roma in Serbia is perhaps even 800,000 . Still, a consolidated estimate is that there are between 450,000 and 500,000 Roma or slightly over 6 percent of the total population, whereas the minimal estimate of Roma population in Serbia would be around 250,000 residents.

In the year 2011, the most Roma were registered in the regions of Southern and Eastern Serbia (38.7\%), then in Vojvodina (28.7\%), in Belgrade region (18.6\%) and in the regions of Šumadija and Western Serbia (14.0\%). The uneven territorial distribution of Roma is also characteristic of Vojvodina 26, where $61.0 \%$ of all Vojvodinian Roma lived in three districts (South Bačka, Central Bačka and и South Banat), mostly in the municipalities of Novi Sad, Zrenjanin, Vršac and Pančevo.

\section{Roma education}

The educational level and educational structure of Roma population are influenced by its social status and its cultural specificities, and they represent one of the darkest aspects in the reality of this ethnic group. The low educational profile is equally contributed by economic poverty and partially ingrained attitudes that they do not even need schooling, as well as inert state apparatus that recognizes the problem, but is 
Table 1. Illiterate Roma in Serbia with 10 or more years, by gender, 2002/2011

\begin{tabular}{|c|c|c|c|c|c|c|c|c|c|}
\hline \multirow{2}{*}{$\begin{array}{l}\text { Census } \\
\text { year }\end{array}$} & \multicolumn{3}{|c|}{ Roma population } & \multicolumn{3}{|c|}{ Illiterate Roma } & \multicolumn{3}{|c|}{ The share in total } \\
\hline & $\Sigma$ & male & female & $\Sigma$ & male & female & $\Sigma$ & male & female \\
\hline 2002 & 84361 & 42408 & 41953 & 16581 & 5019 & 11562 & 19.6 & 11.8 & 27.6 \\
\hline 2011 & 114355 & 58118 & 56237 & 17304 & 5358 & 11946 & 15.1 & 9.2 & 21.2 \\
\hline
\end{tabular}

Source: Statistical Office of the Republic of Serbia, 2014

slow and inefficient in its solution. Thus education becomes a hindrance to the faster socio-economic development, that is a vicious circle where Roma economic weakness represents a consequence of their educational level and vice versa, whereby statistical indicators represent only an expression of educational inferiority of this ethnic community in comparison with other population of Serbia.

Literacy is a main indicator of educational level, which despite the decrease in the illiteracy rate of total Roma population aged 10 years and above from $19.6 \%$ to $15.1 \%$ in the last period between censuses, shows that Roma are still far below the national average $(2.0 \%)$. When observed by regions of Serbia, there are no significant differences since Roma represent an ethnic group with the highest illiteracy rate everywhere.

In Romany population there is a difference in literacy levels between men and women. The illiteracy among women is more pronounced, so that in the year 2011, men made $31.0 \%$ of the total number of the illit- erate Roma, whereas women made $69.0 \%$ of the same number, which means that there were more than two illiterate women per one illiterate man. Reasons for higher illiteracy rate among female than among male Roma population are linked to a whole range of factors, such as attitudes about the significance of education in general, especially for women, the status and role of a woman in the family and so on. Even though the illiteracy is higher in older age groups, the illiteracy of young people (aged 10 to 19 ), who make $8.2 \%$ of their age-mates, is worrisome. Besides, since all the observed generations of the illiterate were born after The Second World War (except those older than 65), it means that the law on compulsory primary education had no effect on them, even though they had to be covered by it.

Levels of educational attainment of Roma in comparison to the relevant levels of the population of Serbia on the whole, show great differences. Every fifth Roma versus every 37th Serbian citizen older than 15 has no educational attainment, whereas more than

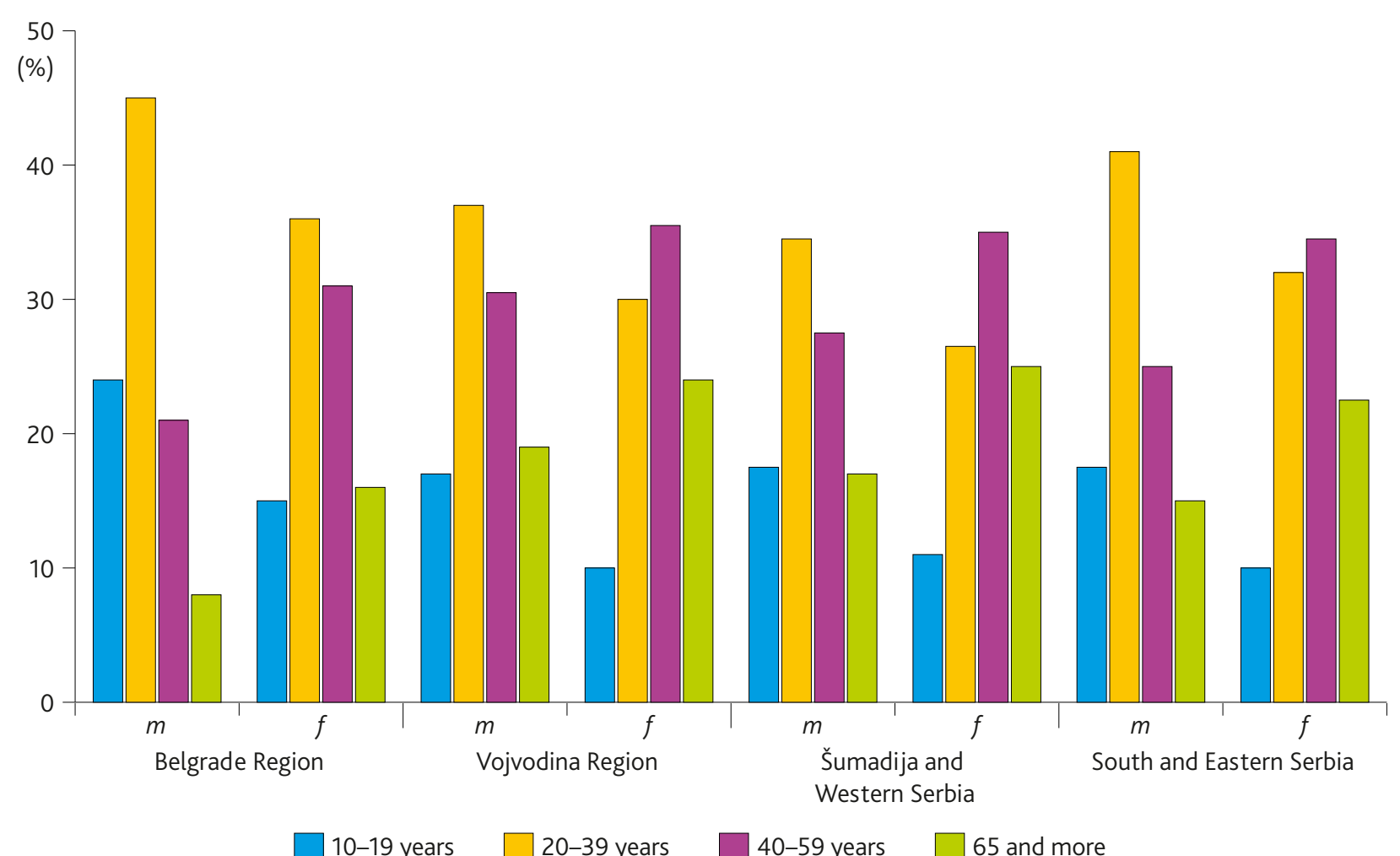

Figure 1. Illiterate Roma population, by age group and regions in Serbia, 2011 (\%).

Source: Statistical Office of the Republic of Serbia2014. Roma in Serbia, 2011, Belgrade. 
Table 2. Level of educational attainment of adult population (older than 15) - for national and Roma population (year 1991, 2002 and 2011)

\begin{tabular}{|l|l|l|l|l|l|}
\hline \multirow{2}{*}{ Educational Attainment } & \multicolumn{2}{l}{ Population proportion (percentage) } & \multirow{2}{*}{ Vojvodina Region } \\
\cline { 2 - 6 } & \multicolumn{2}{|l|}{ Roma population } & \multicolumn{2}{l|}{ Total population } & \multirow{2}{*}{2011} \\
\cline { 2 - 6 } & 1991 & 2002 & 2011 & 2011 & 22.9 \\
\hline No school & 36.6 & 27.4 & 19.5 & 2.7 & 39.9 \\
\hline Incomplete primary school & 26.1 & 34.8 & 34.2 & 10.9 & 27.4 \\
\hline Completed primary school (8 grades) & 27.1 & 28.2 & 33.3 & 20.8 & 9.1 \\
\hline Completed secondary school & 8.1 & 9.2 & 11.5 & 48.9 & 0.4 \\
\hline College or university degree & 0.9 & 0.4 & 0.7 & 16.2 & 0.3 \\
\hline Unknown & 1.2 & 0.0 & 0.8 & 0.4 & 100.0 \\
\hline Total & 100.0 & 100.0 & 100.0 & 100.0 & \\
\hline
\end{tabular}

Source: Statistical Office of the Republic of Serbia, 1991, 2004 and 2011.

a third of Roma (34.2\% versus $10.9 \%$ of the population of Serbia) have no completed primary education. Around one third of Roma (33.3\% versus $20.8 \%$ of people on the state level) have primary education, whereas $11.5 \%$ of Roma ( $48.9 \%$ of people on the state level) have secondary education. There are also striking differences between the percentage of Roma with attained high and higher education (0.7\%) and the percentage of other population of Serbia with attained high and higher education (16.2\%).

When observing the data for Vojvodina, it is noticeable that the largest percentage in the group of Roma older than 15 is made by people with incomplete primary education (39.3\%), then by people with complete primary education $(27.4 \%)$ and by people without education $(22.9 \%)$. The smallest percentages are in groups with completed secondary and higher education. This drastic gap underlines the fact that there are no efficient mechanisms in Serbia necessary to provide the completion of primary education for all. There is a need for the entire line of measures which would contribute to decreasing the high rate of dropping out of the school system among the students of Roma nationality.

The importance of analyzing Romany educational structure by school attainment reflects not only in determining general education, but in emphasizing its dialectic connection with movements and changes in other structures, such as qualification structure of labor force and employees, the tempo of social mobility, demographic structures and so on. Namely, changes in the educational structure of population influence changes in a range of other structures, therefore they influence different social position and status of Roma in the environment they inhabit.

One of the particular problems in Roma education is a so-called "special school” for children with developmental disabilities. Roma make up to about 80 percent of the total number of students in those schools.
Such a high number of Roma children in schools for children with developmental disabilities is a result of the application of inadequate tests, which are used for the categorization of children with developmental disabilities. During the testing of the children, it is not taken into account that Roma children come from extremely socially deprived environments and do not speak Serbian well, which is the language of the test. In a society full of prejudices, Roma children who finished "special schools" do not have any possibility for further education and employment (Humanitarian Law Centre, 2003).

Also, insufficient knowledge of Serbian is a big problem for these children. Such children are entitled to get financial aid for children, care assistance and a full time board in schools with meals and medical protection free of charge.

It is very often the case that the parents themselves support enrolling their children in "special classes", mainly because of free breakfast which is provided for children in these classes. Roma students are afraid of other children, they avoid them, do not socialize with them. Roma children mostly do not complete primary school. A large drop-out of Roma children occurs in the third and fourth grade. Most of Roma children live in difficult financial and housing conditions. A large number of Roma live in improvised houses, without water, electricity or sewage (Humanitarian Law Centre, 2003; Boado, 2011).

Roma are officially acknowledged as a minority, and the Romani language as a mother tongue of an ethnic minority. Practically, education in the Romani language exists only as an optional subject in primary schools - only in the Autonomous Province of Vojvodina.

According to the National Council of Roma National Minority, a large number of Roma children, who are enrolled in regular primary school, do not finish the eighth grade. Out of those who do enroll, 
a significant number drops out of school even after the first grade, and the most dramatic drop out rate starts in the second and third grade, when half of the Roma children who are enrolled in primary school are believed to drop out of school completely. The next phase of a mass drop out from the school system is between the fourth and fifth grade of primary school, which coincides with the transfer from a single teacher schooling system (one teacher for all subjects) to subject teacher schooling system (different teachers for each subject). It seems that, for a significant number of Roma children, this transition is a point when they terminate their schooling. Those who continue education after the fourth grade may leave school after the sixth grade, and only about 1opercenten roll the seventh grade (Open Society Institute, 2007; Boone, Van Houtte, 2013).

Poor education of the parents of Roma children and their attitudes are probably main reasons for the high illiteracy of children and high drop-out rates. Parents do not consider primary education as a priority and a prerequisite for improvement. Furthermore, many of them enroll their children into school only when they need to collect social aid (Čvorović, 2005)

\section{How to improve Roma education?}

Roma assistants in education. One of the ways to improve Roma education in Serbia is to introduce Roma assistants in education. Strategic documents of the government on Roma education had plans for introducing Roma assistants in kindergarten and primary school education, as well as employing coordinators who would work with the families in institutions where there was a large number of Roma children. In 2006/2007, the Mission of OSCE offered a financial and technical support to the Ministry of Education, for introducing the project "Roma Assistants in Education" in primary schools in Serbia. Within the project timeline, by June 2010,the Mission of OSCE would have provided operational support of the Ministry of Education in encouraging and expanding the system of Roma assistants in education (OSCE) (www. osce.org).

Teachers who speak Romani. There are no official data on kindergarten teachers, primary school teachers and subject teachers who speak Romani and use it in classes. NGOs claim that such teachers, even if they do exist, are rare. In the educational process, Roma can only use their mother tongue if they choose an optional subject in primary school, called "The Romani Language with Elements of National Culture". This is only possible on the territory of the Autonomous Province of Vojvodina (Official Gazette of the Republic of Serbia, 2002).
Teaching resources and curricular policy. School Curriculum in Serbia has not been very sensitive to intercultural values and educational needs of national minorities so far. Strategic documents comprise changes in the curriculum which would include multiculturalism and elements of Romani culture. In the long run, curricular reform, as well as a new draft of the Law on textbooks and other teaching resources, should introduce positive changes, even though it is unknown when they will be implemented in practice (Open Society Institute, 2007).

Multiculturalism should be adopted as s value, since pedagogical principles are reflected foremost in the teacher's approach. Teachers must develop sensitivity towards differences. The integration of a student who is different from the others can be successful only where the pedagogical clime is in favour of difference (Konečnik Kotlik, Krečić, 2011).

The school subject "The Romani Language with Elements of National Culture" is being taught only in Vojvodina, which has a tradition of minority education. Optional subject is realized in cooperation with the National Council of Roma Minority and the Ministry of Education and Sport of the Republic of Serbia. Introducing elements of national culture, including Romani culture, would make education more attractive to Roma children, because it would reflect their living environment and contribute to a better acceptance of Roma children by other children and teachers (Open Society Institute, 2007).

\section{Results and Discussion}

The research conducted for the need of writing this paper included 60 teachers of primary and secondary schools in Novi Sad. 30 teachers of this number are employed in primary and 30 in secondary schools. Novi Sad is the capital and the largest town in the Autonomous Province of Vojvodina, it is an academic and multiethnic town. According to the $2011 \mathrm{popu}-$ lation census 3,636 Roma live in Novi Sad. The survey included teachers who work in the town area of Novi Sad as well as teachers who work in suburban areas in order to get better picture of inclusion in smaller settlements. Survey sheets (questionnaires) included 14 questions, and sheets for primary and secondary school teachers differ only in three questions, which provides data comparison of these two data series. Data acquired in this survey are processed in SPSS Statystics. First two questions are general and teachers should make statements about their sex and their workplace in order to answer them. In the rest of the questions teachers are asked to express their attitudes about certain phenomena in inclusive Roma education by using Likert scale. 
There were 12 men and 18 women among primary school teachers, and among secondary school teachers there were 8 men and 22 women. Primary school sample included 20 or $66.7 \%$ of teachers who work in the town area of Novi Sad, whereas 10 or $33.3 \%$ of them work in suburban areas. $210 \mathrm{or} 70 \%$ of secondary school teachers included in the survey work in the town area and $30 \%$ work in suburban areas. This results is not surprising since only few suburban areas have secondary schools.

Sixty per cent of the interviewed primary school teachers as well as $46.7 \%$ of seconadry school teachers very much agreed with the statement that the inclusion of Roma children is good decision of the authorised Ministry of the Republic of Serbia. The fact that $16.7 \%$ of primary school teachers and even $23.3 \%$ of secondary school teachers are neutral about this statement is rather worrisome. This could be explained by the fact that number of Roma children lessens as early as in primary school and very few of them enroll secondary schools. That is why secondary school teachers rarely meet the problem of Roma inclusion in education (Mihajlovic, 2004).

When asked to give their opinion on the statement that Roma children are treated the same as other students at schools the largest number of interviewed (over70\% of primary and over 60\% of secondary school teachers) answered that they agree or that they very much agree, and only one secondary school teacher said that he absolutely disagreed. This indicates the fact that even though Roma are poor, even though they struggle with unemployment and often live in bad social conditions (Kresoja, 2007), they are not badly treated by other ethnic groups.

Thirty per cent of primary school teachers and $20 \%$ of secondary school teachers disagreed with the statement that Roma children successfully master teaching materials, whereas $50 \%$ of primary and $37.7 \%$ of secondary school teachers were neutral about the given statement. These are not good indicators and point out the statement that Roma children don't often have textbooks and other learning aids, so they cannot follow and master teaching materials (Kresoja, 2007).

Secondary school teachers ought to express their agreement with the statement that Roma children are excellently accepted by non-Roma children and the largest percent (33.3\%) of examinees were neutral and $30 \%$ disagreed with the statement.

Over $70 \%$ of primary school teacher and over $60 \%$ of secondary school teachers agreed or very much agreed with the statement that the introduction of pedagogy assistants in education is important because they would help the personnel who work with Roma children. The following figure shows the agreement of primary school teachers with this statement.

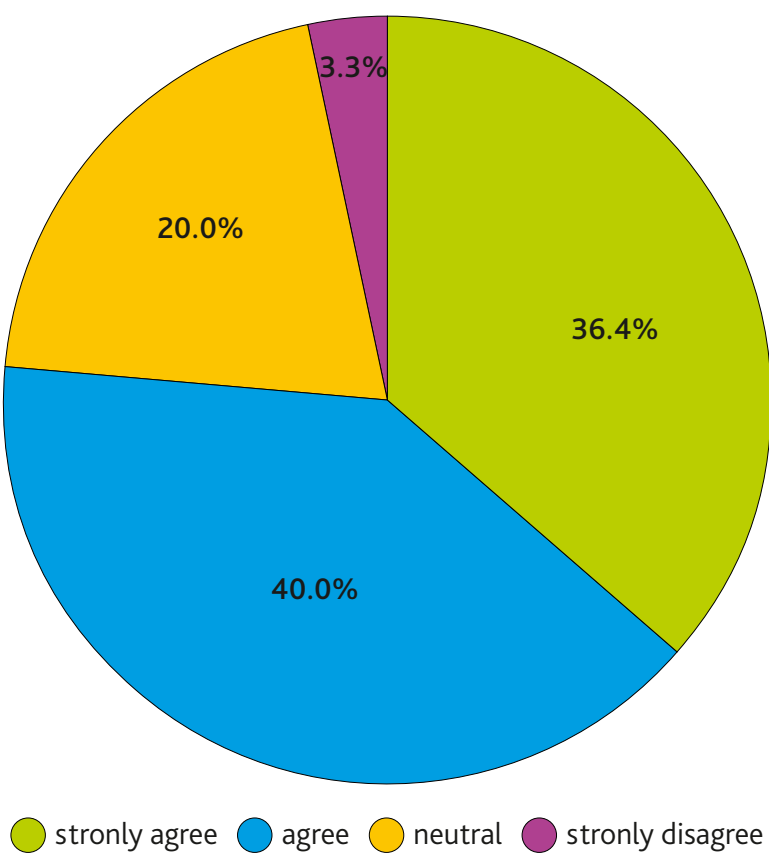

Figure 2. The agreement of primary school teachers with the introduction of pedagogy assistants in education

Pedagogy assistants would help Roma to overcome problems of alienation and non-acceptance (Kresoja, 2007).

Primary school teachers ought to express their opinion about the statement that Roma children do not finish primary education due to their disinter-

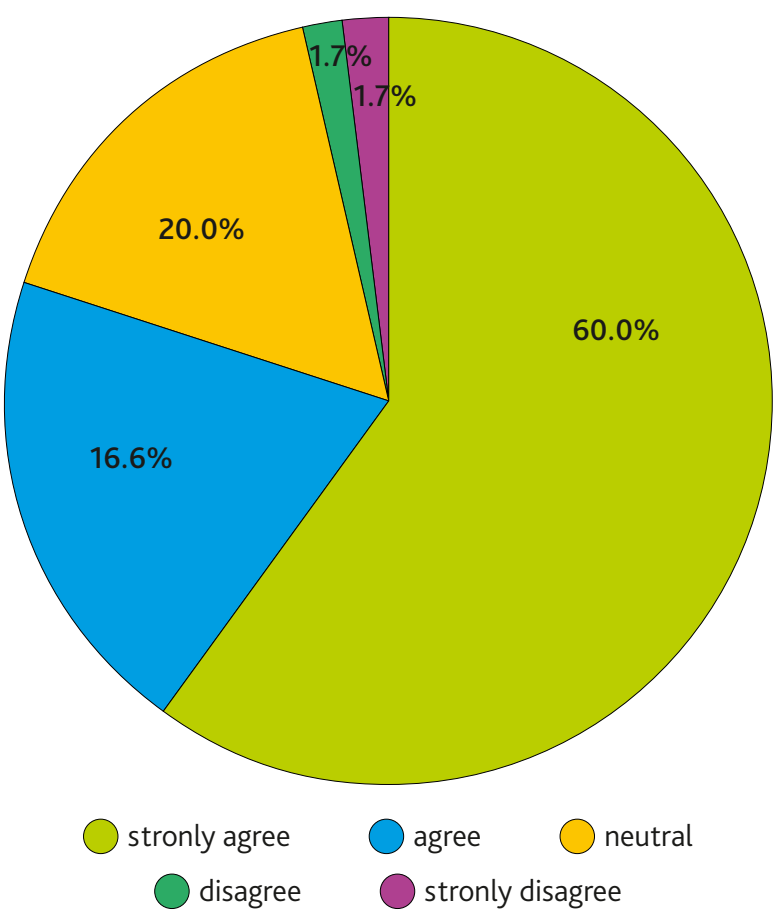

Figure 3. The agreement of primary and secondary school teachers with the statement that inclusion should be planned thoroughly and in cooperation with large number of experts 
est. The largest number of teachers (43.3\%) very much agreed, and $23.3 \%$ agreed with the statement. This is also helped by the fact that large number of Roma children do various economic activities, they help the elderly, beg or collect secondary materials (Adamov, et al., 2012).

Over $80 \%$ of primary school teachers and over $70 \%$ of secondary school teachers agreed and very much agreed with the statement that inclusion should be planned thoroughly and in cooperation with large number of experts.

Many Roma households are not registered, children living in them do not have documents and are not registered as inhabitants of settlements they dwell in, which make their inclusion in educational process difficult to a great extent. Authorities do not very often have proper insight into the right number of Roma children in certain areas, thus successful inclusion requires engagement of large number of subjects (Adamov, et al., 2012).

\section{Conclusion}

The Decade of Roma inclusion strives for a wider access to quality education of Roma. In order to succeed, an intervention is needed by parents and children who need to strive for the quality education, as well as by the state, which has to offer a high level of education for all, including Roma. The Decade strives for the reduction in discrimination and inequality in four key fields: housing, employment, health and education.

Inclusive education is the way leading out of social exclusion. However, Roma in all other countries participating in the Decade are still facing high rates of exclusion out of the quality education. Poverty and marginalization of Roma community increases segregation in schools, by placing Roma students in separate classes and "special schools".

Results obtained from the study "Roma and Education" show that kindergarten institutions are attended by about7 percent of Roma children of kindergarten age. There are expectations that the situation related to inclusion of Roma children in kindergarten institutions will improve with the introduction of obligatory and free "zero grade", having started in the school year 2006/07. According to the National Council of the Roma National Minority, a great number of Roma children who enroll regular primary school never finish the eight grade. The data show that only one third of Roma students who finish the eight grade decide to apply for secondary school enrollment. Unfortunately, if they do decide to enroll secondary school, they choose three-year programs. Those who enroll secondary schools, because of inadequate professional orientation, most often choose profiles which are not sought at the job market.

According to the research conducted for the needs of this paper it has been concluded that the largest number of teachers agree with the statement that Roma children are accepted by non-Roma children as well as with the statement that Roma children would be more successful at school if they had better living conditions. Over $60 \%$ of teachers agree that the introduction of pedagogy assistants would be exceptionally significant for Roma education. Pedagogy assistants would help Roma children to adapt to teaching programme and curriculum. The statement which is considered to be the most significant for Roma inclusion says that inclusion should be planned thoroughly and by large number of experts. The largest number of examinees agreed with this statement, which is a significant guideline for further development and improvement of Roma education.

\section{References}

Adamov, J., Segedinac, M., Kovic, M., Oluic, S.and Horvat, S. 2012. Laboratory Experiment as a Motivational Factor to Learn in Roma Elementary School Children. The New Educational Review 28, 153-164. (in Serbian)

Boado, H. C. 2011. Primary and secondary effects in the explanation of disadvantage in education: The children of immigrant families in France. British Journal of Sociology of Education 32-3, 407-30.

Boone, S. and Van Houtte, M. 2013. Why are teacher recommendations at the transition from primary to secondary education socially biased? A mixedmethods research. British Journal of Sociology of Education 34-1, 20-38.

Claude, C., Chirico, D., McDonald , C., Mohács, V., Peric, T., Székely, Á. 1999. Roma in the educational systems of Central and Eastern Europe. In: Fényes, Csaba, Christina McDonald, and Anita Mészáros, eds. The Roma education resource book. Budapest: Open Society Institute, 20-6.

Crowe, D. 2001. Gypsies of Eastern Europe. Edges magazine, 26.

Hemelsoet, E. 2015. Whose problem is it anyway? Realising the right to education for Roma children in Ghent, Belgium.Romani Studies 25-1, 1-21.

Humanitarian Law Fund (2003). Roma in Serbia. Publikum. Belgrade.

Ivkov, A.2006. Demographic Image of Vojvodina. Zadužbina Andrejević, Belgrade. (in Serbian)

Kicošev, S. 1997.The Changes in the Number and Distribution of Roma in Vojvodina. Cigane moj (Roma in Vojvodina). Edition: The History of Agriculture. Farms and Villages. Book XIII. PČESA. October. Novi Sad - Kikinda. (in Serbian) 
Konečnik Kotnik, E., Javornik Krečić, M. 2011. Teaching for Multicultural Sensitivity: Who Does It Best? The New Educational Review 25, 105-115.

Kresoja, B. 2007. Roma Education in Vojvodina. Lil Inkald, Novi Sad. (in Serbian)

Kyuchukov, H. 200o. Transformative education for Roma (Gypsy) children: An insider's view. Intercultural Education 11-3, 273-80.

Mihajlovic, M. 2004. Needs Assessment Study for the Roma Education Fund, Serbia. Roma Education Fund, Budapest. (in Serbian)

Open Society Institute 2007.Equal Access to Quality Education for Roma.EU Monitoring and Advocacy Program. Education Support Program. Roma Participation Program. Volume I(Bulgaria. Hungary. Romania. Serbia). Monitoring Reports 2007.

Organization for Security and Co-operation in Europe (OSCE). The Mission in Serbia. Belgrade.From http://www.osce.org/

Statistical Office of the Republic of Serbia 2010. Roma in Census. Trial Census of Families. Households and Housing. November 1-15.2009. Belgrade. (in Serbian)

Statistical Office of the Republic of Serbia 1991. Census 1991. Belgrade [CD-ROM]. (in Serbian)

Statistical Office of the Republic of Serbia 2004. Census 2002. Belgrade. (in Serbian)
Statistical Office of the Republic of Serbia 2011. Census 2011. Belgrade. (in Serbian)

Statistical Office of the Republic of Serbia2014. Roma in Serbia, 2011, Belgrade. (in Serbian)

Székelyi, M., György C., Antal Ö. 2003. Ambitious education: The role of family, school and friends in the development of successful Romany life courses. Romani Studies. Fifth Series 13-1, 53-72.

Tanner, A. 2005. The Roma of Eastern Europe: Still Searching for Inclusion.Fromhttp://www.migrationinformation.org/feature/display.cfm? $\mathrm{ID}=308$

The Law on Establishing Particular Competences of theEstablishing Particular Competencies of the Autonomous Province.2002.Official Gazette of the Republic of Serbia. No. 6 Autonoumous Province. (in Serbian)

United Nations Development Programme UNDP, 2005a. The Power of Difference. A Report on Humanitarian Development. Serbia. Country Office in Serbia and Montenegro of the United National Development Program. Belgrade.

United Nations Development Programme UNDP, 2005b. Vulnerable Groups in Central and Southeastern Europe. Belgrade.

Čvorović, J. 2005. Gypsy Ethnic Socialization in Serbia. Ethnographic Institute Gazette. Serbian Academy of Arts and Sciences, LIII, 53, 35-48, Belgrade. 